hostility. The fact that the GMC is not a court has one undesirable consequence. I might well have been able to help Dr Dally if I could have spoken about one of the cases in the hearing. I thought that I could not discuss my patient because I was bound by confidentiality. The lawyers present and the chairman seemed to agree. This put Dr Dally at a great disadvantage.

It is interesting to note that I possess a licence from the Home Office to prescribe heroin, which in some circumstances I could feel to be the righ thing to do, but in the present climate of opinion, as I do not wish to be "savaged," I desist.

In my view it is not Dr Dally that was on trial but the GMC

I fear that it may have become necessary for the medical profession to undertake the difficult and thankless task of reforming the GMC, or no doctor will be safe if he or she offends medical orthodoxy. Let us hope, however, that the GMC realises the dangerous course on which it has set itself and takes corrective action. Let it not follow the usua pattern of English institutions and assume it is perfect, never admitting mistakes or injustice and being unable to reform itself.

Alcoholism and Drug Dependence Unit,

D H MARJOT Ealing Hospital

Middlesex UB1 3EU

SIR,-As the close relative of a former heroin addict, I view the General Medical Council's (GMC) judgment against Dr Ann Dally with considerable disquiet. In the United Kingdom we have an ever increasing drug problem, which the therapeutic "establishment" and the government have failed to control. For many years there have been large yearly increases in the number of recorded addicts, and the number of addicts prosecuted for drug related crime and the quantity of illicit drugs seized continue to grow.

Most addicts have few opportunities to obtain immediate expert and compassionate help. There are insufficient experienced and interested people available to treat addicts, and basic treatment facilities are unavailable in most health authorities. For a population of about 50000 drug addicts in the United Kingdom there are roughly 100 National Health Service beds and 465 places in rehabilitation centres available to provide inpatient treatment. In addition to these gross inadequacies, in recent years certain members of the therapeutic drug "establishment" have attempted deliberately to eradicate any constructive criticism regarding their treatment philosophy, even though their rigid and inflexible methods are associated with a very high drop out and relapse rate. Less than half of the addicts who seek treatment go to "establishment" centres. This "establishment" consists mainly of certain London psychiatrists, who have propagated their inflexible views by establishing power bases within appropriate committees and councils and certain bodies in the medical profession whose function should be to maintain the highest standards of professional integrity.

For a number of years Dr Dally has had the courage to question the relevance of the "establishment" views on treatment and especially the lack of long term maintenance treatment for the genuine chronic addict; small wonder that so many addicts have been profoundly grateful to her for enabling them to lead fairly normal lives. The so called Guidelines of Good Clinical practice in the Treatment of Drug Dependence make no provision for the chronic addict; these "mis-guidelines" are a tragedy for many of our addicts, who face not only the prejudice and isolation of modern society but also that of the medical "establishment."

Dr Dally's treatment from within our profession has fallen far short of the standard that I believe she and we have a right to expect. Freedom from preconceived ideas must be re-established in all matters related to the drugs problem.

Princess Margaret Hospital,

P MONAHAN

Swindon SN1 4JU

\section{Should we be screening for cervical cancer or} breast cancer?

SIR,-If the public respond to the warnings about the acquired immune deficiency syndrome (AIDS) by using condoms and reducing "casual sex" it is true that the incidence of all sexually transmitted diseases, including cervical cancer, will fall. Dr Muriel Purkiss (7 February, p 370), however, has failed to understand that if this should happen (and there is no evidence yet for this in the heterosexual population) we may see a reduction in mortality from cervical cancer only after 15-20 years. ${ }^{12}$ In the mean time registrations for cervical intraepithelial neoplasia stage 3 have quadrupled in a decade in some areas ${ }^{34}$ and a $60 \%$ increase in cancer registrations is projected in 10 years' time. ${ }^{5}$

Britain's poor record for cervical screening is related to the naive belief that screening can be directed at those women most likely to develop cancer; a belief repeated by the junior health minister in "Cervical cancer and men" (Panorama, BBC. 3 November 1986). Experience here and elsewhere has shown this to be ineffective. Though screening needs to be targeted at women (of all ages) who escape population screening, ${ }^{6}$ the greatest reduction in mortality from cervical cancer is achieved with a high population screening index. In British Columbia and Iceland screening indices of around $80 \%$ are associated with a reduction in mortality of more than half. ${ }^{7}$ It is estimated that Britain's policy prevents only $25 \%$ of deaths from the disease. ${ }^{7}$ Britain has an established cervical screening programme that requires increased resources to cater for the rise in cervical intraepithelial neoplasia and the expected rise in cancer and to achieve an $80 \%$ screening index. Vigorous promotion of the cervical screening programme, with increasing awareness of cervical disease, could lead to "safer" heterosexual practice and thereby complement the AIDS campaign. The cost of the additional resources is small compared with the investment required to establish the infrastructure for a national breast screening programme. In seeking to screen for both we should avoid robbing Peter to pay Paul and ending up with two impoverished programmes.

Though the need for a national breast screening campaign should not be undervalued, it should not be compared with that for cervical screening. The cancers differ in aetiology, epidemiology, pathology, and clinical course. The first aim of cervical screening is to detect, at a microscopic level, the premalignant stage at which treatment prevents the development of cancer. Breast screening aims at detecting the early cancer, which stil has significant mortality. Comparison of the crude mortality data for these very different diseases is therefore inappropriate.

Department of Obstetrics and

Peter M Hendy-IbBS

Gynaecology,

St Bartholomew's Hospital,

London ECIA 7BE

1 Canadian Task Force on Cervical Screening. Cervical cancer screening programs. Can Med Assoc f 1976;114:1003-33.

2 Beral V. Cancer of the cervix: a sexually transmitted infection? Lancet 1974; : 1037-40.

3 Scholl SM, Kingsley-Pillers EM, Robinson RE, Farrell PJ. Prevalence of human papillomavirus type 16 DNA in cervica carcinoma samples in East Anglia. Int 7 Cancer 1985;35:215-8. 4 Wolfendale MR, King S, Usherwood MMcD Abnormal cervica smears: are we in for an epidemic? $\mathrm{Br} M e d \mathcal{J} 1983$;287:526-8.
5 Beral V. Predictions of cervical cancer incidence and mortality in England and Wales. Lancet 1986;i:495.

6 British Medical Association, Cervical cancer and screening in Great Britain. London: British Medical Association, 1986.

7 Parkin DM, Nguyen-Dinh X, Day NE. The impact of screening on the incidence of cervical cancer in England and Wales. $\mathrm{Br} \mathcal{F}$ Obstet Gynaecol 1985;92:150-7.

SIR,-Dr Muriel Purkiss's reference (7 February, p 370) to deaths from carcinomas of the cervix and breast in Tower Hamlets for 1980-5 shows a ratio of $1: 5.62$ (37 and 208 deaths, respectively) and states that $18 \cdot 3 \%$ of the deaths from breast cancer were in women aged 54 years and under.

In the same period North West Surrey Health District, with a much higher proportion of women in social classes 1 and 2 and many older women unscreened for cervical cancer, had a ratio of 1:9.19 (36 and 331 deaths, respectively), with $26.9 \%$ of the deaths from breast cancer in women aged 54 years and under. Unofficial figures for 1986 show two and 63 deaths, respectively.

If a massive cervical screening programme is justified the case for breast screening must be overwhelming if shown to be cost effective.

T M C LINDSAY

Department of Community Medicine, Surrey KT16 0QA

Effects of breast conservation on psychological morbidity associated with diagnosis and treatment of early breast cancer

SIR,-Nine years ago I had breast cancer diagnosed and was told that it had been detected at a very early stage. A mastectomy was the only treatment offered, and the possibility of subsequent breast reconstruction was never mentioned. I found the mutilating operation difficult to come to terms with but coped reasonably well for a while, my main preoccupation being that the disease might recur. With time I became more confident about the prognosis, but I also became increasingly depressed about the long term' effects of the operation. I could no longer enjoy buying clothes or sunbathing on holiday, and I found the dragging weight of the prosthesis a permanent discomfort, though I tried many different kinds. Three years after my operation I had a severe nervous breakdown, and although the mastectomy was not the only cause, it was certainly a major contributory factor.

When I moved to Birmingham I was fortunate enough to come under the care of a surgeon whose work I had learned of through the Mastectomy Association. He offered me some hope of improvement through breast reconstruction surgery, and three years ago I had a prosthesis implanted. This was, and still remains, a miracle to me. I felt normal again, and consequently the quality of my life was transformed. Perhaps best of all was that once the more devastating effects of the mastectomy were no longer so evident the ever present fear of cancer receded too.

My own experience leads me to believe that it is in the longer term that the real psychological benefits of lumpectomy treatment can be found. After having come to terms with the shock of a cancer diagnosis and, hopefully, having survived a reasonable time without relapse, a woman can begin to look forward again to a life without the mutilating scars of a mastectomy. Of course, I accept that, when offering treatment, a surgeon's first priority must be to save a patient's life and that there are many women who, when faced with a diagnosis of breast cancer, would choose to have a mastectomy. If, however, evidence continues to support the view that in early breast 
cancer intervals without relapse and survival rates in patients treated by mastectomy are comparable with those in patients treated by local incision and radiotherapy I hope that the trend towards conservative surgery will continue, so that eventually every woman with breast cancer for whom it is deemed possible may be offered an alternative to a mastectomy. I did not have this choice until six years after the operation, but for the rest of my life I shall remain grateful to the surgeon who enabled me to feel whole again.

GILL A MCCLARE

University of Birmingham

Birmingham B12 2T J

\section{Prejudice against doctors and students from} ethnic minorities

SIR,-Dr Richard Smith's leading article (7 February, p 328) on the research study by the Commission for Racial Equality has provided a valuable stimulus for further discussion of this important, but sadly long neglected, subject.' The main thrust of the study should be the plight of the doctors who were born in this country and wholly trained in British universities but are also being discriminated against. This should not be tolerated, and health authorities that still practise such discrimination should be advised not to do so. Table III of the study shows the percentage of overseas doctors who are consultants in different regional health authorities and highlights the discrepancies that demand an explanation. ${ }^{1}$ Regional distribution of consultant posts among doctors born overseas shows an average of $17 \%$ for England and Wales as a whole and above average for most of the regions, including the prestigious London postgraduate teaching hospitals, but East Anglia and South Western regions have an unexplained low $9 \%$. This may mean that the people living in these two regions are not getting the best available treatment. It is for the government to act effectively. I have one suggestion, which is that no more merit awards should be distributed to these regions until they mend their ways. There is enough evidence for the government to act immediately through the Department of Health, and the British Medical Association, royal colleges, and faculties should stimulate urgent reform before it is too late for the students and doctors who were born in this country and regard themselves as part of the United Kingdom.

If the names of members of the different regional awards committees on distinction awards could be published yearly, as they were in 1977 by Anaesthesia,$^{2}$ at least some of the secrecy would be abolished, and a healthy discussion might ensue about the system that has caused anxiety not only in the medical press ${ }^{3}$ and in the present study but also in the lay press. ${ }^{4}$ More recently, the merit award system has been criticised by both sides in parliament. $^{s}$

General Hospital

B Thalayasingam

County Durham DH8 0NB

1 Anwar M, Ali A. Overseas doctors: experience and expectations. London: Commission for Racial Equality, 1987.

2 Anonymous. Association news and notices. Anaesthesia 1977;32: 939-42.

3 Lester E. Sex distribution of distinction awards. Br Med $\mathcal{J}$ 1980;280: 198 .

4 Anonymous. Curing consultants. [Editorial.] The Times 1985 July 8:13.

5 Anonymous. NHS merit awards attacked. The Times 1987 Feb $10: 4$

SIR,-I have not seen the original report from the Commission for Racial Equality, but it seems surprising that Dr Richard Smith (7 February, p
328) did not mention the needs and expectations of minority groups in relation to the training or appointment of doctors in the National Health Service. If doctors from minority groups, whether ethnic, racial, or religious, are not to be appointed to posts in deference to the supposed demands of the majority then members of minority groups will eventually be unable to find like minded doctors to look after them. Those with conscientious objections to abortion have already seen the virtual exclusion of doctors who share their views from consultant posts-and even sometimes from training levels. Recent evidence suggests that unwillingness to provide a full range of artificial contraceptives is proving an impediment to appointment in general practice, and this may also in time pose difficulties for those patients who share the same beliefs. Although it would clearly be very difficult to ensure a fair geographical spread of doctors from minority groups in relation to patient demand, I hope the problem will not be overlooked entirely in any review of appointment procedures.

I M JESSIMAN

\section{Chislehurst,} Master, Guild of Catholic Doctors

Kent BR7 5ES

SIR,-Dr Richard Smith (7 February, p 328) derides "non-academic suitability-whatever that is" as a valid criterion in the selection of medical students. Our selection process alone has been rigorously studied and the results published; we cannot answer for other schools. Shortlisting for interview here depends on three separate factors, which we have called academic ability, interests, and community service. ${ }^{1-3}$ Applicants with nonEuropean surnames had lower scores in interests and community service, and therefore a lowe proportion of them were interviewed than of those with European surnames. ${ }^{4}$ These differences entirely explained the reduced likelihood of acceptance of applicants with non-European surnames by any of the British medical schools to which candidates in our study had applied. The applicants themselves thought that selectors should look for many personal qualities, including ability to listen and to communicate widely, commitment compassion, dedication, inquisitiveness, and motivation. ${ }^{5}$ Furthermore, they criticised strongly excessive reliance on examination grades.

The prospectus of this medical school (which has not been accused of discrimination) makes it clear that we look for students of good academic ability with diverse backgrounds and interests who will contribute to our community here during their training and to a wider world thereafter. Within those guidelines we take no account of sex, creed politics, ethnic group, wealth, or influence. This is what we understand by "equal opportunity policy." Did Dr Smith have something else in mind when he used this term?

May we repeat what we wrote to you in January 1985. "If, however, society feels that the diminished likelihood of entry of some groups is of sufficient concern to mean that selection should be based entirely on academic achievement, then it must also accept the consequences of that decision, which are that candidates currently regarded in open competition as less suitable for admission would be admitted, and that candidates in general would feel that selection was not based on the wider principles of natural justice, which include selection based on assessments of personal qualities as well as of academic ability."

Peter Richards I C McManus St Mary's Hospital Medical School London W2 IPG
McManus IC, Richards P. Audit of admission to medical school: I-Acceptances and rejects. Br Med 7 1984;289:1201-4.

McManus IC, Richards P. Audit of admission to medical school II-Shortlisting and interviews. Br Med F 1984;289:1288-90. 3 McManus IC, Richards P. Audit of admission to medical school: III-Applicants' perceptions and proposals for change. BrMed J 1984;289:1365-7.

McManus IC, Richards P. Admission to medical school. BrMed 1985;290:319-20.

McManus IC. Medical students: origins, selection, attitudes and culture. London: University of London, 1985:253. (MD thesis.)

SIR,-Dr Richard Smith (7 February, p 328) misquotes the publication on overseas doctors by the Commission for Racial Equality. The North Western Regional Health Authority had the highest number of overseas trained consultants and Mersey Regional Health Authority the lowest number, not percentages, as was stated. The true picture is not surprising in view of the relative sizes of the regions. When percentages are compared the north west was near the top for both consultants and training grades and Mersey about average.

Dr Smith implies that the selection of the regions for study was related to their being at the extremes. There is no indication in the report as to why the two were chosen. At the time of the study there were about 4500 hospital doctors in the two regions, of which about 1650 were from overseas. An unknown number of these doctors were approached by letter, and an unstated and self selected number responded. From these a sampling frame was compiled, but the nature of this frame is not stated. The notes on methodology in the report states: "Each overseas trained doctor was matched, as far as the limited numbers available would allow, with a white British doctor with the same qualifications and, if possible, of the same sex. Grade and age were not used in the matching process." Dr Smith suggests that this might be called a "case-control" study. I suggest that if the report were one of a new method of treatment and the results published after a similar process of self selection it would not be described as an important development.

Criticism of the methodology of the survey should not devalue those parts of the reports that do not depend on comparisons derived from the interviews. Facts reported from official statistics and the beliefs and experiences of doctors are valuable contributions, even if the comparisons of percentages are not. One of the recommendations is that health authorities should implement the race relations code of practice as employers. The North Western Regional Health Authority has already adopted an equal opportunities policy that incorporates this code. Another recommendation, curiously unrelated to the substance of the report, is that the BMA as a trade union should adopt a policy of equal opportunity as an employer. Has it?

North Western Regional Health Authority

D H VAUGHaN

**The BMA is an equal opportunity employer. - ED, $B M \mathcal{J}$

SIR,-Discrimination on the grounds of sex, race, religion, and nationality is perhaps commonplace in many countries, but it is now fairly clear that discrimination due to prejudice is the main problem for overseas doctors in the United Kingdom.

I find it difficult to accept that "overseas doctors are less well trained, less competent, and speak poorer English than British doctors . ..,", as Dr Richard Smith questions (7 February, p 328), as any overseas doctor coming to the United Kingdom since 1975 has had to prove his worth in all of these three aspects in the TRAB test, which has subsequently become the PLAB test. Once such a 